\title{
Communications for Peacebuilding: Conflict Resolution Skills and Strategies of Lupon Tagapamayapa in Selected Communities of Sarangani Province
}

\author{
Julnes U. Jumalon ${ }^{1}$, Russtum G. Pelima ${ }^{12}$, Kloyde A. Caday ${ }^{1}$ \\ ${ }^{1}$ English Department, College of Social Sciences and Humanities, Mindanao State University- \\ General Santos City \\ ${ }^{2}$ Corresponding author, dodoipelima@gmail.com
}

Received: December 15, 2017; Accepted: January 13, 2018

\begin{abstract}
The Lupon Tagapamayapa (LT) of the two barangays in Sarangani Province- Barangay Baliton in Glan and Barangay Upo in Maitum- were studied as to the skills and strategies they employ in resolving petty conflicts as a means of communication towards building peace in the community. Using qualitative-content analysis, multiple sources of data were used namely FGD, KII, Venn Diagram and Observation with video and note taking. It was found out that the LTs of both barangays Baliton (mostly populated by Blaan indigenous people) and Upo (with the Tboli natives) - applied similar processes and procedures in resolving conflicts prescribed by the Local Government Code such as: Greetings and Introduction, Conflict Settlement Proper and The Settlement and Resolution. On language use and communication skills, both LTs demonstrated competence both in verbal and non-verbal communications. In verbal communication, the LT used carefully chosen words, aphorism, rhetorical question and analogy; while in non-verbal communication, the LT regulated the tone and volume of the voice, used appropriate hand gestures and eye contact. Further, the LT employed strategies such as collaboration, compromise, spiritual advice, and active listening. Land conflict is the most common case resolved by the LT. This is followed by debts and assault. Misunderstanding and differences in principles and value judgment are the most common factors that cause conflicts in the community. Aside from these, jealousy, theft, selfishness, vices, and broken relationships were also identified.. The study also revealed factors that could hinder or facilitate the conflict resolution, which were differing goals and levels of compromise and frustration. With the personal, interpersonal, cultural, and structural changes among the members of the LT, the study recommends further research on the competence of LT among remote communities and or other indigenous groups in Mindanao for a broader and more enhanced justice system in the barangays.
\end{abstract}

Keywords: verbal communication, non-verbal communication, aphorism, rhetorical question, spiritual advice, Lupon Tagapamayapa (LT), conflict resolution, Baliton, Upo, Sarangani, Glan, Maitum, qualitative content analysis, KII, Venn diagram, FGD

Conflict and disagreement among members of a community may arise due to several reasons such as incompatible values and expectations, personality clashes, miscommunication, unequal distribution of power and moral or cultural differences among others. Often communities do not have trained personnel to effectively manage conflicts or are themselves unaware of certain skills and strategies to do so.

Accordingly, the success of any conflict resolution can be largely dependent upon effective communication between or among the aggrieved parties. Managing communication and promoting healthy and non-violent conflict resolution should be a goal of any mediator. This is the reason why there is a global sense of urgency to heighten 
awareness on the use of communications for peacebuilding and to conduct studies and researches along this area.

Moreover, the presence of professional mediator/s can help ensure that the conflict is resolved while helping to protect the interests of both conflicting parties from possible legal actions that could arise if the situation is not properly handled.

Fortunately, in many barangays in the Philippines, there is a constituted group of mediators called the Lupon Tagapamayapa which was created by virtue of Republic Act (R.A.) No. 7160 otherwise known as the "Local Government Code of 1991", wherein Article 387 (b) of the law provides that "there shall be in every barangay a Lupong Tagapamayapa". This organized group has the power to convene conflicting parties and try to settle disputes in the barangay level as much as they could. Thus, this study tried to document the performance of the Lupon Tagapamayapa in selected communities of Sarangani Province. Sarangani is part of the South Cotabato-Sultan KudaratSarangani-General Santos City (SOCSKSARGEN) development cluster, and is linked by paved roads to the international airport and harbor of Gen. Santos City. The province is divided into two parts, separated by the Sarangani Bay and General Santos City, and it used to be part of South Cotabato until it was made an independent province in 1992. (NSCB, 2014).

The pre-identified communities for this study are among the ethnic groups found in Sarangani which are the Blaans of Glan and the Tbolis of Maitum. The Blaans represent the largest minority in Sarangani and are mostly found in the municipalities of Malapatan, Glan, Alabel, Maasim and Malungon. Tbolis live mostly in Maitum, Kiamba and Maasim (Baluma, 2014).

Finally, the researchers hope that this study could contribute to the empirical body of peace efforts in the Mindanao region. The aim of this study is to determine and analyse the communications for peace-building of the Lupon Tagapamayapa as they facilitate conflict negotiations among selected communities in Sarangani. The specific objectives are as follows: (1) to assess performance of the Lupon Tagapamayapa in conflict resolution of petty community and family conflicts, specifically on the following areas: process and procedures used, language use and communication skills, conflict resolution strategies, common conflicts resolved; (2) to determine the common causes of conflicts resolved by the Lupon Tagapamayapa; (3) to list the factors that hinder/ facilitate resolution of petty community and family conflicts in Barangay Upo, Maitum and Baliton, Glan; (4) to determine changes in the perceptions of the Lupon Tagapamayapa as a result of the conflict resolution in terms of personal outlook, relational (interpersonal), cultural and structural.

\section{Materials and Methods}

This study used descriptive-content analysis design using qualitative data gathering tools to answer the research questions. Multiple sources of data were used and each one is described next.

\section{Key Informant Interviews (KII)}

Key Informant Interviews were conducted both with the Lupons and the conflicting parties involved. This was used to collect basic information about each Lupon and representatives from each conflicting party. Some questions were answerable only by yes or no.

\section{Focus-Group Discussion}

Focus-Group Discussion was conducted among Lupons and selected members of conflicting parties. The FGD was used to ensure the consistency of collected data along with the KII data.

\section{Observation}

Video and Notetaking were done all throughout the conflict resolution process to capture in toto actual language use, other communication skills and also non-verbal communication.

\section{Venn Diagram}

The researchers used the Venn Diagram, a tool that illustrates the relationships between the Lupon officials and the conflicting parties to unobtrusively determine the conflicting parties' perception about the Lupon Tagapamayapa.

\section{Sampling Procedure}

The main respondents of the study were the members of the qualified and composite members of the Lupon Tagapamayapa present during the actual Conflict Resolution process observed by the researchers. All of these officials formed part of the Observation, the Key Informant Interview (KII) and Focus Group Discussion (FGD). Moreover, some selected members of the conflicting parties functioned as Part of the KII, FGD and Venn Diagram.

Furthermore, the purposively selected sample of respondents/informants were selected on the basis of controlling key variables such as: he should be a Lupon Tagapamayapa member in the community of Brgy. Upo and Brgy. Baliton. The other set of respondents would constitute part of 
the conflicting parties involved in the actual conflict negotiation process.

The identification of the Lupon Tagapamayaypa was done in consultation with the Barangay Captains of the pre-identified barangays in Baliton, Glan and Upo, Maitum.

All the Lupons in each barangay were included in the KII and the FGD. However, only a few selected members of the conflicting parties were part of the FGD and Venn Diagram.

\section{Results and Discussion}

The data gathered and presented have been used to answer the specific objectives raised at the onset of this study.

\section{Process and Procedure Used}

The Lupon Tagapamayapa of Brgy. Baliton and Brgy. Upo observed the same standard process and procedure of conflict resolution set by the Local Government Code.

\section{Greetings and Introduction}

First, the Presiding Officer (PO) greeted the parties involved and introduced the matter to the body. Then a Christian or Muslim prayer was offered. The sessions of the conflict negotiations basically entail the immense use of appropriate language in communication-expressing sincerity, fairness, justice for all sides, understanding, consideration, courtesy and truth wrapped in one as entailed in a belief to one Supreme Being. Such explains why each session of the LT starts with a prayer. After the prayer, the Presiding Officer set the house rules in conflict settlement, to wit: nobody was allowed to talk when not asked, nor banged the table, pointed at someone, brought weapons and firearms inside the room, and never interrupted a person speaking. The PO directed the barangay secretary to document the entire process.

\section{Conflict Settlement Proper}

The settlement proper begins with the complainant narrating the incident/s that caused the conflict, followed by the respondent's version of the story and his defense. The Presiding Officer (PO) clarifies the issue, signaling the complainant to comment on it. If any of the party speaks in a dialect (Blaan or Tboli), the Lupon translates the explanation in the lingua franca (Cebuano) so everybody can understand. According to the respondents from Brgy. Baliton, there were times that the PO would call for a 15-minute recess when handling complex issues so that heated arguments could be pacified. The Lupon would be divided into two and would approach each party to give some advice.

Once the Presiding Officer has no more further questions regarding the matter and the conflicting parties have been given enough time to present themselves, there will be an evaluation from the Lupon. The evaluation is structured in the following manner: (1) greeting, (2) comments, opinions, and suggestions, and (3) wrap up.

\section{The Settlement and Resolution}

The decision is declared once the presiding officer has listened to the position of both parties. Periodically the PO asks the barangay secretary to read the text within the hearing of everyone to ensure the conciseness and consistency of what has been agreed by the parties as mediated by the LT. The settlement must be mutually acceptable to both sides. Afterwards the two parties are told to shake hands and reconcile, followed by a closing prayer. Finally, the parties and the Punong Lupon sign the minutes and the amicable settlement.

The Lupons of Brgy. Baliton reported that after a couple of days, they would check up on the settled parties and follow these procedures to maintain peace: (1) restoration, or getting the parties back to their relationship, (2) reconciliation or forgiveness, and (3) counseling, or offering pieces of advice to both the complainants and respondents.

Based on the CS documented, the Lupon from Brgy. Baliton conformed to the procedures and rules they mentioned during the focus group discussion. They were very particular with the house rules as they were able to stop the parties from pointing fingers at each other. They also directed the person speaking to stand up to follow the protocol, and ordered one to speak aloud so everybody inside the hall could clearly listen to and understand the testimony. They corrected a complainant for being out of topic. They also prevented him from blurting out statements that would waste time and complicate the dispute. Finally, the Lupon removed the language barrier by translating a Blaan testimony to Bisaya so the non-Blaan speakers can note and comprehend the respondent's defense.

However, the CS that transpired in Brgy. Upo was not consistent as compared to Brgy. Baliton. There were many interruptions when one was talking. They were not able to stop one complainant from displaying inappropriate gestures, such as pointing a finger to the opposing side. Before arriving at a resolution, there were impertinent chats that prolonged the CS. Besides that, the LT were passive; the PO (who is a Brgy. Kagawad) dominated the discussion, while the LT did not offer much evaluation on the issue. 
The efficiency of the LT in Brgy. Baliton can be traced to their experience in CS. Some of them have been serving the community as a Lupon for 6 years. They are also very active in their community involvement. In addition, their self-worth and dedication to the service are significant in championing peace in their barangay. They identify themselves as mediators of peace, and the conflicting parties have high respect and trust on the LT in their ability to solve the disputes in the area.

On the other hand, the LT in Brgy. Upo have not yet firmly established their sense of identity and authority in the community because of lack of training and experience. There is no fixed schedule on their CS, and they are only called when the need arises. The cases go to the Brgy. Captain first, and the opposing parties prefer the issues to be resolved by the Captain herself, and not by the LT.

\section{Language Use and Communication Skills}

In this study language use and communication skills included both Verbal and Non-Verbal communications.

\section{Verbal Communication}

The preselected communities of this project are the Blaans and Tbolis of Sarangani Province. Obviously, their mother tongue is the Blaan and Tboli ethnic languages. But they also speak the more dominant major languages such as Cebuano, Ilocano and Tagalog languages. In these barangays, however, Cebuano Bisaya is the predominant medium of communication, the "lingua franca," mixed with the mother tongue of the respondents.

It was observed that in terms of verbal use of language, there was no language barrier, despite the diversity in language since the conflict participants are either bilingual or multilingual. That means they either have passive or active control of the languages. The Lupon Tagpamayapa who are multilingual readily translated the respondents' language use, every time they (the respondents) revert to their mother tongue.

Accordingly, the Lupon Tagapamayapa demonstrated competence in their word choice and style as they try to peacefully mediate the conflicting parties.

\section{On Word Choice}

The members of the LT appeared to have fair skills in their word choice and style in using these to exude patience and interest. The LT members showed no bias or undue inclination. They always seem to clarify points from both contending parties and mediating using words with positive connotation and phrases which always appear to be peace-building expressions. The verb hangyo (appeal) and pangayo (ask, request) are commonly used by the LT members, in whatever needed form to express polite request but noticeably sounding firm and authoritative.

The LT used appeal to emotion as they dig for hidden reasons for animosity to allow for forgiveness to prevail by using such phrases as $s a$ atong kasing-kasing (in our hearts) and sa atong huna-huna (to our minds). There are also abstractions which appear to strike a cord in the hearts of those in the contending parties such as magkasinabot (to understand), pasaylo (forgiveness), edukasyon (education). It is noteworthy how the LT refers to the respondent as inosente (innocent) to show that the respondent has no access to education, and is financially incapable of paying any monetary penalty.

\section{On Styles and Genre}

We observed various language styles in each of the two Lupons. These styles represented the LT's language use strategies as a tool to broker peaceful relationship between the contending parties.

The arguments used aphorisms - the sayings, common proverbs or maxims or adages that commonly colored or spiced up the native conversations of the Blaans and Tboli people. As the aphorism embodies general truths observed over many generations, it is common in the speech of LT to emphasize for example the bad effects of alcohol, paraphrasing a familiar Filipino saying, "Ang alak nilalagay sa tiyan, hindi sa ulo." Asking rhetorical questions seems to be commonly done by the LT merely to share information or knowledge. The LT likewise tends to demonstrate growing skill to manage the avoidance of prolonged discourses and achieve more straightforward discussions of how to address the parties' needs and reconciliation of both sides.

\section{Use of Nonverbal Communication as Strategy in Conflict Management}

The LT uses encoding skills or expressively communicating emotions, attitudes and other messages using nonverbal cues. These nonverbal cues are facial expression, gaze, gestures, body language, behavior and paralinguistics. It appears that the LT tries to use the foregoing to maintain calm and collected during the sessions. Voice regulation in terms of tone and volume is another strategy the LT tries to master and use with the Presiding Officer (PO) maintaining a monotonous intonation refraining from changing pitch of voice to avoid 
being suspected of bias. Variation of tone is practiced like being stern when encouraging respondent to tell the truth, modulating voice when asserting LT authority. Attentive listening to either side tends to be palpable indicated by pauses for evaluating. The gazing behavior is another strategy the LT seems to really work hard at. Such is done through good eye contact indicating genuine interest to what is shared or explained. Appropriate hand gestures to describe and illustrate things or to emphasize points ot to avoid uttering some exact words which could trigger acrimony. An example in Barangay Baliton, a hand gesture was observed to avoid saying buang (crazy). Another cue is by directing someone using an open hand instead of pointing a finger, an insulting or provocative gesture.

Other conflict resolution strategies which are basically observed in conflict management are applied and used by the LT. These are collaboration and compromise, but adding one more with religious dimension is seized and used by the LT. This is the use of spiritual advice that tends to engender forgiveness.

Active listening by the LT tends to promote trusts and sense of being important to the contending parties.

The study also surfaced sources and kinds of conflicts such as differences in principles and value judgment, jealousy, theft, selfishness, vices and ruptured relationships. It could be due to these that hateful words, curses, grievances and animosity flare up in communities.

Thus in the two communities studied conflict settlement tends to demonstrate how goals, level of compromise and levels of frustration and contentiousness can be manipulated and redirected to resolve disputes and foster peace. Such seems to be achievable through the communication skills and strategies displayed by the members of the Lupon Tagapamayapa.

It was our impression that the interest, assiduousness and diligence of the LT members fuel their relatively productive functioning. Not withstanding their seemingly creditable accomplishments in conflict negotiations, there appear certain critical skills and capacities they need to acquire more, foremost of which are training in communication particularly in appropriate translations from dialect to dialect and basic nuances of the law in its language and intent.

\section{Conflict Resolution Strategies}

Based on the FGD and the outcome of the conflict resolution, the strategies that the Lupon used were collaboration, compromise, spiritual advice, postponement, and active listening.

\section{Collaboration}

According to Dontigney (2004), collaboration is one of the five strategies in managing disputes, and this strategy was employed to find solution to the case at hand. It can be observed from the documented actual settlements that all members, including the opposing sides, brainstormed on solutions acceptable to everyone. The PO gave liberty to the LT to offer suggestions and insights regarding the conflict, and asked the complainants what could satisfy their demands. Then the LT would evaluate a possible solution to the problems laid down before them.

The LT established the notion that their vital role was to settle and mediate on the problem, and not to decide who was wrong or right. They democratized their way of settlement by letting the parties agree or oppose the settlement the LT had thought of. Thus, everybody was a participant and a problem solver in the conflict negotiation in barangays.

\section{Compromise}

Another strategy is compromise, which happens when both sides give up elements of their position to establish peace (Ibid.).

Sacrificing a part of one's wants was very hard in the part of the complainants of Brgy. Baliton, but they agreed on a compromise in the end. The complainants of Brgy. Baliton initially wished for an endorsement from the Brgy. Captain to bring the case to the municipal court and asked for a penalty to the damages done by the respondent. However, the LT did not agree that the complainants' proposition would resolve the dispute, considering the gravity of the matter did not warrant bringing it to a higher court. It also considered the financial capacity and maturity of the respondent to pay for his misconduct and damages. At the same time, the respondent was asked to reduce his alcohol intake and to promise not to be violent again or the matter would be endorsed to the municipal court. The complainants agreed to give up on their demand to end the dispute and to forgive the respondent.

\section{Spiritual Advice}

The LT believed that a sincere advice that touches on the parties' spirituality would be an effective way to solve conflicts in the community. In the CS that transpired in Brgy. Baliton, a Lupon paved the way for the opposing sides to forgive each other and prevented the complainant's de- 
mand for an endorsement from the barangay as well as the penalty against the respondent. After his advice, a member of the complainant's side was persuaded to stop asking for sanction, Said member though requested for an undertaking which stated among others that a second offense of the respondent would constrain the former to elevate the matter to the higher court for appropriate legal actions.

\section{Active Listening}

Rogers (1980) defined active or attentive listening as "giving one's total and undivided attention to the other person and tells the other that we are interested and concerned... We listen to the words of the other, but we also listen to the messages implied in between the words. We listen to the voice, the appearance, and the body language of the other... We simply try to absorb everything the speaker is saying verbally and nonverbally without adding, subtracting, or amending" (cited in Robertson, 2005). The LP employed this strategy to emphasize the importance of effective and objective discourse inside the CS. He stressed that appropriateness in body language and hand gestures, silences, showing interest in the addressor, and reflecting before speaking are the skills they had to develop to be an active listener.

The LT in Brgy. Baliton added that they had to be equally critical to both sides and to weigh out the reasons first before arriving at a resolution. It was evident on the way the CS was organized, that, before they express their position on the matter, they allowed the two parties to finish testifying and narrating the events that led to the issue or dispute.

\section{Common Conflicts Resolved}

Through the key information interview, the Lupons identified the most common conflicts that they settled in the community by enumerating three to five cases.

Figure 1 shows that land conflict is the most common in the community, followed by debts, and assault. They also mentioned other disputes such as theft, violence due to alcoholism, illegal drugs, slander, and violence against women and their children.

It can be inferred that land conflicts are inevitable in Brgy. Baliton and Brgy. Upo, for these are communities where most of the members venture into farming as their source of income. Besides, almost all of the interviewees are farmers. The cases they cited on the said disputes were misunderstanding on land boundaries, and problems on land ownership due to lack of legal documents, specifically those in writing. They opined that awareness and knowledge about land ownership could lessen, if not completely eradicate, further land conflicts in these communities.

\section{Common Causes of Conflicts in Communities}

In answering the KII, the LTs were asked to enumerate three common factors from which conflicts originated, and they were made to explain why these factors led to disputes among/between people in the community during the FGD.

It can be gleaned from Figure 2 that mis-

\section{COMMON CONFLICTS RESOLVED}

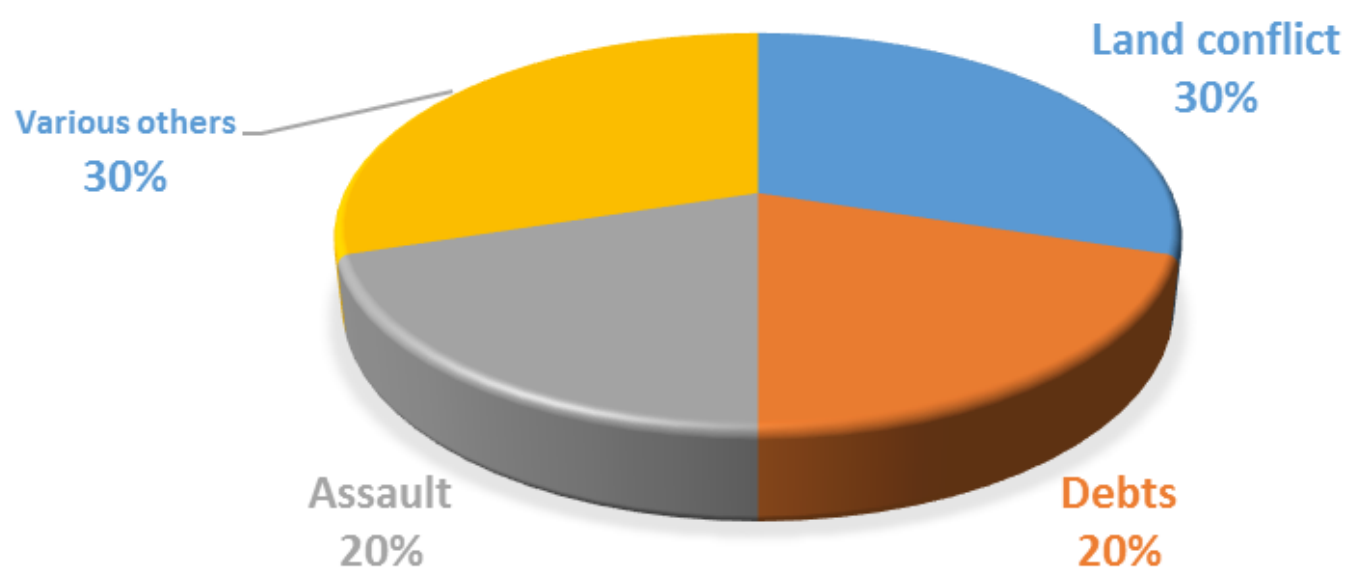

Figure 1. Common conflicts resolved in Brgy. Baliton and Brgy. Upo. 


\section{FACTORS THAT CAUSE CONFLICTS}

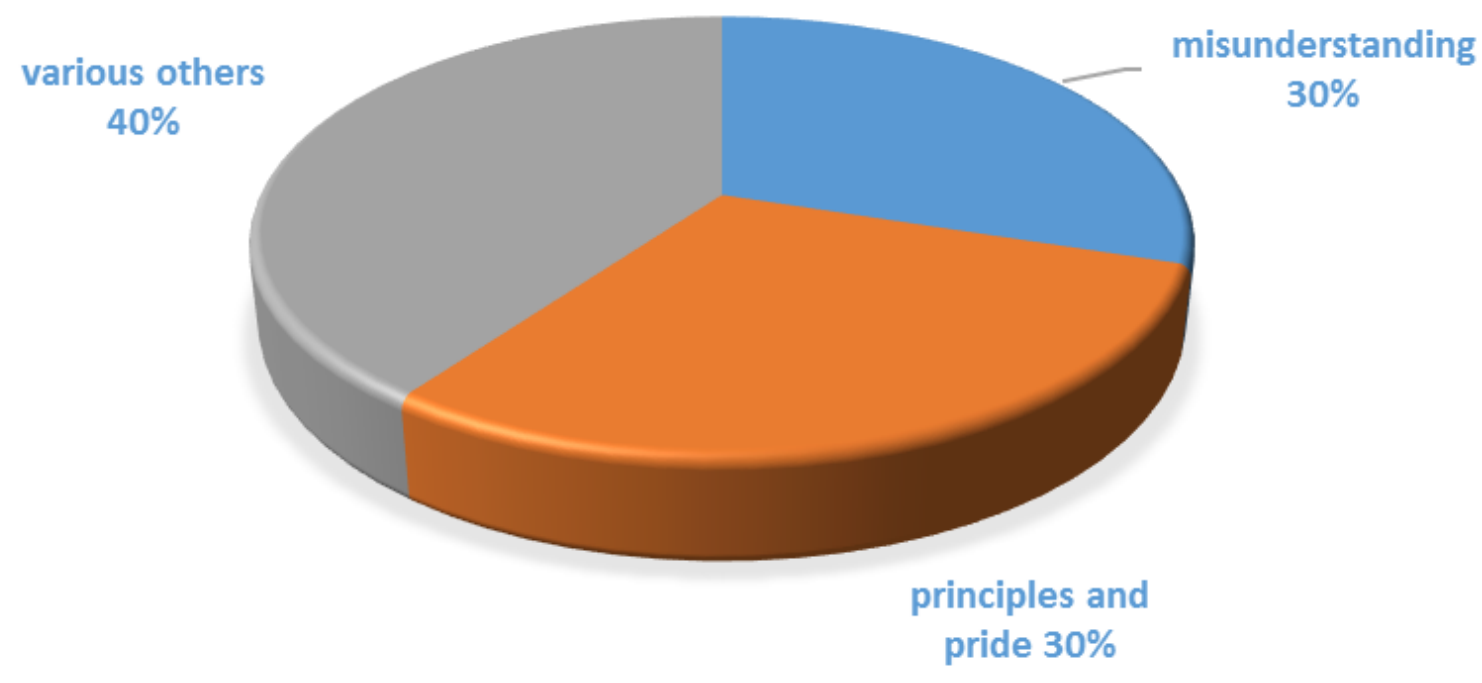

Figure 2. Common causes of conflicts in the community.

understanding and differences in principles and value judgment are the most common factors that trigger conflicts in the community. Aside from these, they also identified jealousy, theft, selfishness, vices, and broken relationships as factors igniting fight among people in their barangay.

They explained that misunderstanding resulted to adverse effects on relationships because failure to understand the communication drew negative reactions from the one who misinterpreted the remarks. The negative reactions may be hateful words, curses, grievances, and the like. The LT's would then attempt to resolve conflicts by going back to the root/s of the problem and 'repair' the parts where pronouncements were not understood, were exaggerated, or were understated. Too, they believe that since the problems started with words, They should also be mended by words and dialogue - a diplomatic discourse and nonviolent means of conflict resolution.

Differences in principles and pride prove to be sources of conflicts in interpersonal relationships. Coming from various economic and social and educational level and background, it was inevitable that they would perceive one another in varying degrees of valuing self and others.

All respondents in both cases belong to the lower economic social class as they are paid laborers who failed to comply with what were expected of them. The complainants on the other hand are relatively socio-economically well-off who hire the services of the respondents.

\section{Resolutions \\ Factors that Hinder/Facilitate Conflict}

The conflict settlements documented in the communities demonstrate how goals, levels of compromise, and levels of frustration can be manipulated to resolve disputes and foster peace among the parties involved.

\section{Goals and Level of Compromise}

The different goals the parties aim for may impede on a mutually beneficial solution. The first case in Baliton (Grave Threat/assault) at first tended to be left unresolved due to incompatible goals, as the complainant did not want to forgive the respondent and wanted to raise the case to the municipal level with all legal measures, if the respondent would not pay the "danyos" demanded by the complainant. But there were Lupons who asked about the capability of the respondent to pay in cash the demanded damages. They found out that the respondent was jobless and unschooled. After a more reasonable discourse, the final agreement was to forgive the respondent and for him to say SORRY to his grandfather in-law and to the other affected relatives such as the son of the complainant. This forged a compromise agreement between them.

In the case of the undelivered prepaid lumber, the resolution came after a long, heated and one- sided outburst of emotion from the complain- 
ant who waited for over a year before she finally decided to seek the help of the Lupon Tagapamayapa. Amidst these, the respondent remained calm and silent as he listened to the complainant express her frustrations against him.

The respondent, however, justified that the pieces of wood were not delivered because he couldn't afford fuel and because the woods, too, weren't usable. Based on the intervention of the LT a settlement was agreed that the respondent would deliver the lumber within a prescribed time and date. Failure on his part to do so would constrain the Lupon to endorse the case to a higher court..

\section{Levels of Frustration}

Levels of frustration were also depicted as the complainants in Brgy. Baliton expressed their humiliation due to the respondent's assault; they were also concerned with their lives as the respondent threatened to kill the complainant. The respondent's alcoholism and misbehavior were seen as a big problem in their community. On the other hand, the complainant in Brgy. Upo stressed that the construction of their house had been delayed because the respondent failed to deliver the materials needed for it despite the cash advances the complainant paid and her good treatment of the respondent. She also disclosed that the Php 27,000.00 paid in advance to the respondent was the hard-earned salary of her husband who was working overseas.

Both parties showed the capacity to forgive, compromise and accept the evaluation of the LT. It made the CS easier and successful. The complainants had to give up more than they even wanted in settlement because the respondents' situation and financial status were also considered. The frustration levels were also set aside as both parties wished for the conflict to be settled. For instance, the complainants in Brgy. Baliton insisted that an endorsement from the barangay to bring the case to the municipal court for corrective purposes be issued, but the LT argued that an endorsement letter would not be beneficial to both sides. The complainants suggested that the respondent be charged with the penalty out of the damages done, but after realizing the situation of the respondent, they did not ask for penalty. Instead, they forgave the man. Thus, it implies that to facilitate conflicts and to arrive at a better resolution, one must be willing to give up a part of his/her desire and to consider the other side's position, to compromise and to submit to the measures pondered by the authorities. Lastly, one must put out past grievances and hard feelings and be ready to forgive.

Changes in the Perceptions of the Lupon

\section{(Wustrow, 2014)}

During the FGD, the members of the LUPON gave their insights and instances on how their experiences as Lupon help them in their personal growth, relationship with other people, and in their views about culture and the government.

\section{Personal Outlook}

The outcomes of the Lupon conflict resolution greatly help them to apply the strategies they used to solve problems on their own. Also, in settling conflicts, they learned that every problem could be settled through understanding, sincere and diplomatic dialogue and not through violence and vengeance.

Being part of the conflict resolution, the LT claim they are faced with the challenge to solve the problems in the community, and eventually help them grow mentally, emotionally and socially as they go about their role in conflict settlement. In turn, the community looks up to them as they try to solve conflicts through the good attitude of a true leader and a compassionate human being.

Finally, their duties as a Lupon help boost their self-esteem and sense of fulfilment.

\section{Relational Changes}

The Lupon considered that one of the rewards of their duty in the barangay is the good relations they are able to maintain in their homes. More importantly, it trained them to be good guardians at home. It also enabled them to expand this harmonious relationship with their peers, workmates, and relatives. The respondents remarked that it would be a shame for them to be considered mediator if they couldn't even solve their problems inside their homes.

\section{Cultural Changes}

The barangays understand and respect their diverse cultural orientations. Thus, they make it a point that the conflicting parties and the Punong Lupon must both belong to the same cultural/ethnic group during CS for that matter. This attitude is another proof of the Lupon Tagapamayapa's desire to foster peace and harmony amidst a culturally diverse community.

\section{Structural Changes}

The Lupons receive P450.00 per month as their honorarium. They admit that what they receive cannot compensate for the services they offer, but helping their community (Brgy. Baliton) gives them a sense of fulfillment.

\section{Conclusion}

The Lupon Tagapamayapa functions ac- 
cording to the goal and purpose for which it has been created through the Local Government Code. It helps to maintain peace and harmony in culturally and linguistically diverse settings.

The LT of each barangay demonstrates loyalty and faithfulness to the process and procedures outlined in the law on conflict mediation. They need more trainings, though, and are interested in attending trainings and seminars to enhance and improve their skills in conflict mediation and negotiation.

The study proved that the LT's communication skills both verbally and non-verbally are satisfactory. Their being multilingual is a great help in facilitating conflict settlement among groups of different ethnolinguistic background. Their skills result in the forging of smooth and resolved cases.

Communities need the Tagapamayapa people since conflicts are inevitable.

The universality of the nature of factors that may hinder or facilitate conflict mediation is proven and tested in this study.

Life gets meaningful and purposeful when one becomes a useful and productive citizen of a community in any way one can (Lupon Tagapamaуара).

The study also recommends that more assessment research projects on a wider scale should be conducted on the performance of the Lupon Tagapamayapa in the same areas specified in this study. The LT must be exposed to more trainings and seminars to keep them updated with recent trends and developments in conflict resolution. Likewise, the LT should be fairly compensated by the Local Government to uplift their socioeconomic well- being as peacekeepers of the community. Finally, since Sarangani Province has a total of 42 PDCs (Peace and Development Communities), further study of each of these communities' unique experience in conflict management could help build peace in the community more effectively.

\section{References}

Ambady, N., \& Rosenthal, R. (1998). Nonverbal Communication. In H. S. Friedman (Ed.), Encyclopedia of mental health (Vol. 2). San Diego: Academic Press.

Approach 3rd edition. Belmont, CA: Wadsworth.

Baluma, Teogenes, F. MD. MHA, MDM, FPCHA, CESO III Sarangani Province.
Cohen, Ryan. (2001). Meaning, Interpretation and Negotiation. USA: Blackwell Publishers.

Dent, Warren. (2008). Program on Negotiation Pedagogy. Ireland: Teaching Resource Center.

Dontigney, Eric. (n.d.). Rettrived from: http:// smallbusiness.chron.com/5-conflict-managementstrategies-16131.htmlhttp://

Friedrich, P. (2007). Language, Negotiation and Peace: The Use of English in Conflict Resolution. Bloomsbury Academic.

Guiam, Rufa. C. (2013). Gender and conflict in Mindanao. Foundation

Jackson, S.L. (2009). Research methods and statistics: A Critical Thinking

Johnson, Marlene. (2014). Retrieved from: www.org. tutorials/effective conflict resolution/ language.

"List of Provinces". PSGC Interactive. Makati City, Philippines: National Statistical Coordination Board. Retrieved 13 May 2014.

Robertson, KM, Active listening: More than just paying attention, Australian Family Physician, 2005, 34 (12), pp. $1053-1055$

Smith, Mary John. 1988. Contemporary communication research methods. California: Wordsworth Pub. Co. Inc.

The Local Government Code of the Philippines Book III Local Governement Units www.dilg.gov.ph/PDF_File/reports_resources/ DILG-Resources-201162-99c00c33f8.pdf

Varner \& Beamer. 1995. Intercultural communication in the workplace. USA: Donneley and Sons Comp.

Wustrow, Kurve. 2014. Nonviolent conflict transformation: training manual for a training of trainer's course. 